OPEN ACCESS

Edited by:

Mary Anne Sampaio Melo,

University of Maryland, Baltimore,

United States

Reviewed by:

Isadora Martini Garcia,

Federal University of Rio Grande do

Sul, Brazil

Ingrid Fernandes

Mathias-Santamaria

University of Maryland, Baltimore,

United States

${ }^{*}$ Correspondence:

Sharadwata Pan

sharadwata.pan@tum.de

Specialty section:

This article was submitted to Biomaterials,

a section of the journa

Frontiers in Materials

Received: 09 February 2021

Accepted: 06 April 2021

Published: 22 April 2021

Citation:

Jeevanandam J, Danquah MK and Pan S (2021) Plant-Derived Nanobiomaterials as a Potential Next Generation Dental Implant Surface Modifier. Front. Mater. 8:666202. doi: 10.3389/fmats.2021.666202

\section{Plant-Derived Nanobiomaterials as a Potential Next Generation Dental Implant Surface Modifier}

\author{
Jaison Jeevanandam¹, Michael K. Danquah² and Sharadwata Pan ${ }^{3 *}$ \\ 'Centro de Química da Madeira (CQM), MMRG, Universidade da Madeira, Funchal, Portugal, ${ }^{2}$ Department of Chemical \\ Engineering, University of Tennessee, Chattanooga, TN, United States, ${ }^{3}$ TUM School of Life Sciences, Technical University \\ of Munich, Freising, Germany
}

Dental implants resemble synthetic materials, mainly designed as teeth-mimics to replace the damaged or irregular teeth. Specifically, they are demarcated as a surgical fixture of artificial implant materials, which are placed into the jawbone, and are allowed to be fused with the bone, similar to natural teeth. Dental implants may be categorized into endosteal, subperiosteal, and zygomatic classes, based on the placement of the implant "in the bone" or on top of the jawbone, under the gum tissue. In general, titanium and its alloys have found everyday applications as common, successful dental implant materials. However, these materials may also undergo corrosion and wear, which can lead to degradation into their ionic states, deposition in the surrounding tissues, as well as inflammation. Consequently, nanomaterials are recently introduced as a potential alternative to replace the conventional titanium-based dental implants. However, nanomaterials synthesized via physical and chemical approaches are either costly, non/less biocompatible, or toxic to the bone cells. Hence, biosynthesized nanomaterials, or bionanomaterials, are proposed in recent studies as potential nontoxic dental implant candidates. Further, nanobiomaterials with plant origins, such as nanocelluloses, nanometals, nanopolymers, and nanocarbon materials, are identified to possess enhanced biocompatibility, bioavailability and no/less cytotoxicity with antimicrobial efficacy at low costs and ease of fabrication. In this minireview, we present an outline of recent nanobiomaterials that are extensively investigated for dental implant applications. Additionally, we discuss their action mechanisms, applicability, and significance as dental implants, shortcomings, and future perspectives.

Keywords: dental implants, nanobiomaterials, biocompatibility, endosteal, titanium alloys, zygomatic implants

\section{INTRODUCTION}

In general, implants are synthetic components that are placed in a living organism as a replacement for a damaged part and eventually supports the normal activity of the organism (Prakasam et al., 2017). In humans, dental implants are the most common types of implants, which are widely utilized to replace damaged or malfunctioning dental parts throughout the world (Rupp et al., 2018). The dental implants are generally necessary for humans, when there is a dental damage due to accident, lifestyle changes including excessive smoking and alcohol consumption, and several 
complications that lead to gum damage. Further, the usage of dental implants has been increased recently due to their safe clinical results and low cost (Sanguida et al., 2019). Conventionally, these dental implants are artificial materials, which are designed as teeth to replace the damaged or irregular teeth (Neldam and Pinholt, 2012). It can be noted that the history of dental implants to replace damaged dental parts in humans dated back to $600 \mathrm{AD}$, where the Mayan civilization has been found to utilize small sea shell parts resembling insertions with the purpose mandibular teeth substitution (Abraham, 2014). Due to the recent advantages in biomedical science and surgical techniques, dental implants are also defined as a surgical fixture of artificial implant material, which are placed into the jawbone and are allowed to be fused with the bone, similar to a natural teeth (Huang et al., 2017). Further, screws to fix the teeth and braces to align the teeth arrangement for facial symmetry were also considered as dental implants (Travess et al., 2004). Endosteal, subperiosteal and zygomatic are the classes of dental implants, which were classified based on the placement of implant "in the bone" or on top of the jawbone under the gum tissue. Zygomatic implants are distinct from conventional implants, where they are anchored in the zygomatic region of the bone rather than maxilla (Henri Diederich and Abou-Rabii, 2019). Generally, titanium and its alloys, such as nitinol were used as a common and successful materials for dental implant applications (Shah et al., 2019). However, these materials are identified to undergo corrosion and wear, which can lead to degradation into their ionic state, deposition in the surrounding tissues and inflammation (Park et al., 2020).

Nanomaterials are gaining essential significance due to their exclusive properties in various biomedical applications, ranging from drug delivery to biosensors (Jeevanandam et al., 2020a); Tan et al., 2019; Pan et al., 2021; Tan et al., 2020). Chemical and physical approaches are the commonly used synthesis methods to yield smaller sized novel nanomaterials (Jeevanandam et al., 2016). However, the toxicity toward bone cells (chemically synthesized nanomaterials are mostly toxic toward pre-osteoclast (RAW264.7) and pre-osteoblast (MC3T3-E1), depending on their dose and concentration), less biocompatibility depending on their size, surface, and composition, and high cost of these nanoparticles are the limitations of these nanomaterials, which has led to the introduction of biological approaches or biosynthesis, i.e., utilization of biomolecular extracts of microbes and plants (Ha et al., 2018; Rasouli et al., 2018). Among biosynthesis approaches, microbial-mediated synthesis of nanomaterial called nanobiomaterials has been identified to yield non-toxic nanomaterials, however, the process is tedious, requires high reaction time and difficult to fabricate nanomaterials with discrete architectures (Andra et al., 2019). Thus, currently, plant isolates are comprehensively employed to synthesize non-toxic nanomaterials with distinct morphologies and surface properties (Shanmuganathan et al., 2019). These plant-derived nanobiomaterials are recently under extensive research to be included as novel materials to manufacture the next generation dental implants as a potential alternative for conventional implant materials (Augustine and Hasan, 2020). This review is an overview of recent nanobiomaterials, which are under extensive research for dental implant applications. Further, significance of these nanomaterials as dental implants, mechanism of action, drawbacks and future perspective will also be discussed.

\section{CONVENTIONAL DENTAL IMPLANTS AND THEIR LIMITATIONS}

Conventional dental implants are broadly made up of metals, ceramics, polymer or combination of all these materials as composites. In the category of metals, titanium, titanium alloys such as nitinol (nickel and titanium), stainless steel, gold alloys, tantalum, and cobalt chromium alloy are commonly used to fabricate dental implants. Further, alumina, betatricalcium phosphate, carbon materials, carbon-silicon, zirconia, bioglass, and zirconia-toughened alumina are the ceramics and polysulfone, polytetrafluoroethylene, polyurethane, polymethymethacrylate, polyethylene, and polyether ether ketone are the polymers, which are used to fabricate conventional dental implants (Osman and Swain, 2015). These dental implants are usually beneficial for the replacement of single tooth without high costs, compared to the traditional fixation of dental prostheses (Vogel et al., 2013). Apart from cost-based advantages, conventional dental implants behave similar to natural teeth, last for a long time, prevent bone loss, provide stability to adjacent teeth, reduce gum disease complications and prevent facial sagging and premature aging-related issues (Li J. et al., 2020). Further, the mechanical strength of these materials, evaluated via both in vitro and in vivo studies, is on par with natural bone and dental tissues, which makes them the most common implant materials (Li J. et al., 2020). However, these materials undergo degradation during interaction with the biological fluids, leading to corrosion and wear, which can be deposited in the surrounding cells or tissues and cause inflammation (ApazaBedoya et al., 2017; Park et al., 2020). Furthermore, osteoporosis, immunocompromised patients of diabetes $[3.89 \%$ of failure rate (Chrcanovic et al., 2014)], Acquired Immunodeficiency Syndrome (AIDS) condition [10\% of failure rate (May et al., 2016)], smoking and radiotherapy in head and neck cancers are the factors that can lead to dental implant failures (Bazli et al., 2020). Additionally, conventional dental implants involve high initial costs for mandibular edentulism patients, compared to mucosa-borne dentures (Vogel et al., 2013). Thus, nanomaterials are currently under extensive research and are used in certain cases as a surface modifier of conventional dental implants or to fabricate novel nanomaterial-based implants for eliminating the limitations of conventional dental implants.

\section{NANOMATERIALS IN DENTAL IMPLANT APPLICATIONS}

Nanomaterials are recently incorporated in several aspects of dental applications, such as preventive dentistry, dental implants, restoration of implants, periodontics, endodontics, dental tissue engineering, and 
scaffolds (Zafar et al., 2019). Among these applications, carbon, metal, polymer, and metal oxide nanoparticles and certain nanocomposites were used for dental implant applications.

\section{Metal Nanomaterials}

Metal nanomaterials, such as gold, silver, platinum, copper, and selenium possess enhanced antimicrobial properties. Hence, these nanomaterials find applications in the form of an antimicrobial, surface coating substance of the conventional dental implants, to prevent them from microbial attackmediated degradation (Parnia et al., 2017). Likewise, these nanoparticles are incorporated with conventional dental implant materials, such as titanium and hydroxyapatite also possess osteointegration property for 12 weeks (Woźniak and Markuszewski, 2019). Recently, silver nanoparticles are deposited on the surface of commercially pure titanium via exposed air "laser ablation" to enhance the dental graft antibacterial property (Boutinguiza et al., 2018). Further, it has been identified that the chitosan-gold nanoparticles possess enhanced ability to deliver c-myb gene at the target site, which is a transcription factor belongs to myoblastosis family, that can control survival, differentiation, cell proliferation, and death. The c-myb delivery by the gold nanocomposite has facilitated dental implant osseointegration in ovariectomized rat model (Takanche et al., 2018). Furthermore, nanocrystalline titaniumcopper alloy has demonstrated a strong biocompatibility, antibacterial, osseointegration, and mechanical properties to be a highly beneficial orthopedic material, especially for dental implant application (Moniri Javadhesari et al., 2020). Moreover, silver nanoparticle decorated graphene nanocomposites were identified to possess osteointegration property with enhanced antibacterial activity against an oral pathogen named Aggregatibacter actinomycetemcomitans along with Streptococcus mutans, Candida albicans, and Lactobacillus acidophilus (Peng et al., 2017).

\section{Metal Oxide Nanomaterials}

Nanosized metal oxides are highly stable, compared to metal nanoparticles, which brands them highly beneficial as antimicrobial agents with high osseointegration and mechanical property to be coated on the surface of the insert (Ghiciuc et al., 2017). Recently, silver and zinc nanoparticles embedded in the layers of titanium oxide nanotube has shown enhanced antimicrobial actions toward oral microbes, for instance S. mutans, C. albicans, and Candida parapsilosis, and are proposed to be beneficial toward the management of dental contagions (Roguska et al., 2018). Likewise, porous tantalum oxide nanoparticles along with calcium phosphate and osteoconductive elements were fabricated into a core-shell structure and are proposed as a next generation dental implant material (Fialho et al., 2021). Similarly, nanocomposites of titania-zinc oxide fabricated as thin films on the substrates of silicon exhibited enhanced biocompatibility and antibacterial activity, which can be a potential coating films for the dental implant applications (Goel et al., 2019).

\section{Carbon and Polymer Nanomaterials}

Carbon-based nanoparticles, for instance carbon nanotubes, graphene, diamond nanoparticles, and quantum dots were also utilized as a coating or dental implant material. However, these carbon nanomaterials are incorporated with metallic or polymer nanomaterials as nanocomposites to retain their mechanical properties and enhance their biological properties. In a recent study, graphene incorporated with zinc oxide as nanocomposite film has been found possess ability to protect the surfaces of dental implants from cariogenic $S$. mutans bacteria (Kulshrestha et al., 2014). Likewise, carbon-based nanodots, nanotubes, nanofibers, fullerenes, graphene derivatives, and nanocrystalline diamonds were reported to be beneficial a surface functionalization material to improve the surface property of the dental implant (Kang et al., 2021). Besides, nanosized polymers or polymer matrix composites, such as natural or biopolymers namely poly (lactic acid) and chitosan, synthetic polymers including polyetheretherketone (PEEK) and glycidyl methacrylate/triethylene glycol dimethacrylate (BisGMA/TEGDMA) are widely fabricated as nanoparticles or incorporated with nanoparticles to exhibit enhanced efficiency in dental implant applications (Kadambi et al., 2021).

\section{LIMITATIONS OF NANOMATERIALS AS DENTAL IMPLANTS}

It may be noted that all the nanomaterials mentioned in the previous section are fabricated via either chemical or physical approaches. These nanomaterials possess significant properties, such as chemical compositions similar to teeth and its components, wettability, surface energy, and surface roughness, which makes them highly beneficial for the dental applications (Rasouli et al., 2018). However, the chemicals used for the fabrication of these nanomaterials are toxic toward human cells and high energies are involved in the nanomaterial formation, which has been identified as potential limitations to recommend them for large-scale commercial dental implant applications (Jeevanandam et al., 2020b). The toxicity of these chemical or physical synthesized nanomaterials depends on the type of reducing and stabilizing agent used for nanomaterial fabrication, size, morphology, and surface functional groups as well as their surface charge of nanomaterials (Ganguly et al., 2018; Qu et al., 2018). Further, it can be noted that the traces of reducing and stabilizing agents in the nanomaterials, will also affect their biocompatibility, bioavailability, bioreactivity, and eventually cause acute or chronic side effects (Zhang et al., 2017). Furthermore, the costs involved in the chemical and physical synthesis are higher to be recommended for large-scale commercial nanomaterial synthesis (Jamkhande et al., 2019). Thus, biosynthesis approaches via microbes and their extracts has been introduced as an effective green synthesis approach for the formation of nanomaterials with less toxicity and high biocompatibility, compared to conventional chemical and physical synthesis approaches (Khan and Lee, 2020). Fungi, bacteria and algae are the most common microbes, which find applications 
toward the microbial production of nanomaterials (Yadav et al., 2020). Microbial nanomaterial fabrication outside the cellular space, especially using the biomolecules extracted from the microbes are extensively used to form nanoparticles, compared to the intracellular approach, where the extraction and purification of nanomaterials is tedious (Li et al., 2017). Even though, microbial synthesis is beneficial in yielding non-toxic, smaller sized nanobiomaterials, there are certain limitations that constrains their exploitation in large-scale biomedical applications (Kulkarni et al., 2021). Bacteriamediated nanomaterial synthesis possess limitations, such as high time consumption and reduced control over the size, crystallinity, and morphology. Likewise, difficulties in downstreaming process and $24-120 \mathrm{~h}$ for nanomaterial formation are the limitations of fungal and algal-mediated nanobiomaterial synthesis (Jeevanandam et al., 2016). Hence, extracts of plants known as phytochemicals are introduced as an alternative and potential reducing and stabilizing agent for the formation of nanobiomaterials to be beneficial in biomedical applications, especially for dental implant applications as summarized in Table 1.

\section{PLANT-DERIVED NANOBIOMATERIALS AS DENTAL IMPLANTS}

In recent times, several nanobiomaterials have been fabricated using plant extracts to be employed in the dental implant applications, as an alternative to conventional dental implants as shown in Figure 1. Recently, it has been reported that the $71.5 \mathrm{~nm}$ sized spherical gold nanobiomaterial, that are synthesized via the aqueous bark extract of Salacia chinensis, can be utilized for dental implant application. The in vitro studies revealed that the synthesized nanobiomaterial possess superior stability in blood components, such as $2 \%$ of human serum albumin $0.2 \mathrm{M}$ of histidine and $0.2 \mathrm{M}$ cysteine of $2 \%$ bovine serum albumin. Further, the study showed that the phytosynthesized nanomaterial are cyto-compatible and compatible toward blood, such as periodontal fibroblasts and erythrocytes. Besides, the gold nanobiomaterial increased the cell viability of human MG-63 bone osteosarcoma cell lines, which indicates that the nanomaterial possess enhanced osteoinductive potential, which can be useful for dental graft treatment as a "bone inductive agent" (Jadhav et al., 2018). Similarly, another study showed

TABLE 1 | Advantages and limitations of conventional and nanomaterial-based dental implants.

\begin{tabular}{|c|c|c|c|}
\hline Dental implant materials & Advantages & Limitations & References \\
\hline $\begin{array}{l}\text { Metals, ceramics, } \\
\text { polymers, alloys, and } \\
\text { composites }\end{array}$ & $\begin{array}{l}\text { Low cost, compared to prostheses and behave } \\
\text { similar to natural tooth }\end{array}$ & $\begin{array}{l}\text { Degradation in biological fluids, corrosion and } \\
\text { wear, and leading to inflammation }\end{array}$ & $\begin{array}{l}\text { Vogel et al., 2013; } \\
\text { Apaza-Bedoya et al., 2017; } \\
\text { Li J. et al., 2020; Park } \\
\text { et al., } 2020\end{array}$ \\
\hline $\begin{array}{l}\text { Physical and chemical } \\
\text { synthesized nanomaterials }\end{array}$ & $\begin{array}{l}\text { Chemical compositions similar to teeth and its } \\
\text { components, wettability, surface energy, and } \\
\text { surface roughness }\end{array}$ & $\begin{array}{l}\text { Toxicity toward human cells, low } \\
\text { biocompatibility, bioavailability, and high cost for } \\
\text { synthesis }\end{array}$ & $\begin{array}{l}\text { Zhang et al., 2017; Rasouli } \\
\text { et al., 2018; Jeevanandam } \\
\text { et al., 2020b }\end{array}$ \\
\hline $\begin{array}{l}\text { Microbial synthesized } \\
\text { nanobiomaterials }\end{array}$ & $\begin{array}{l}\text { Less toxicity, high biocompatibility, and } \\
\text { biological property }\end{array}$ & $\begin{array}{l}\text { Longer synthesis time, reduced control in } \\
\text { stability, and tedious down-streaming process }\end{array}$ & $\begin{array}{l}\text { Jeevanandam et al., 2016; } \\
\text { Khan and Lee, } 2020\end{array}$ \\
\hline $\begin{array}{l}\text { Plant-derived } \\
\text { nanobiomaterials }\end{array}$ & $\begin{array}{l}\text { Less toxicity, control in stability, ease in down } \\
\text { streaming process, biocompatibility, and bone }\end{array}$ & $\begin{array}{l}\text { Difficult to modify shape, lack of in-depth dental } \\
\text { studies }\end{array}$ & $\begin{array}{l}\text { Sundeep et al., } 2017 \\
\text { Jadhav et al., } 2018\end{array}$ \\
\hline
\end{tabular}

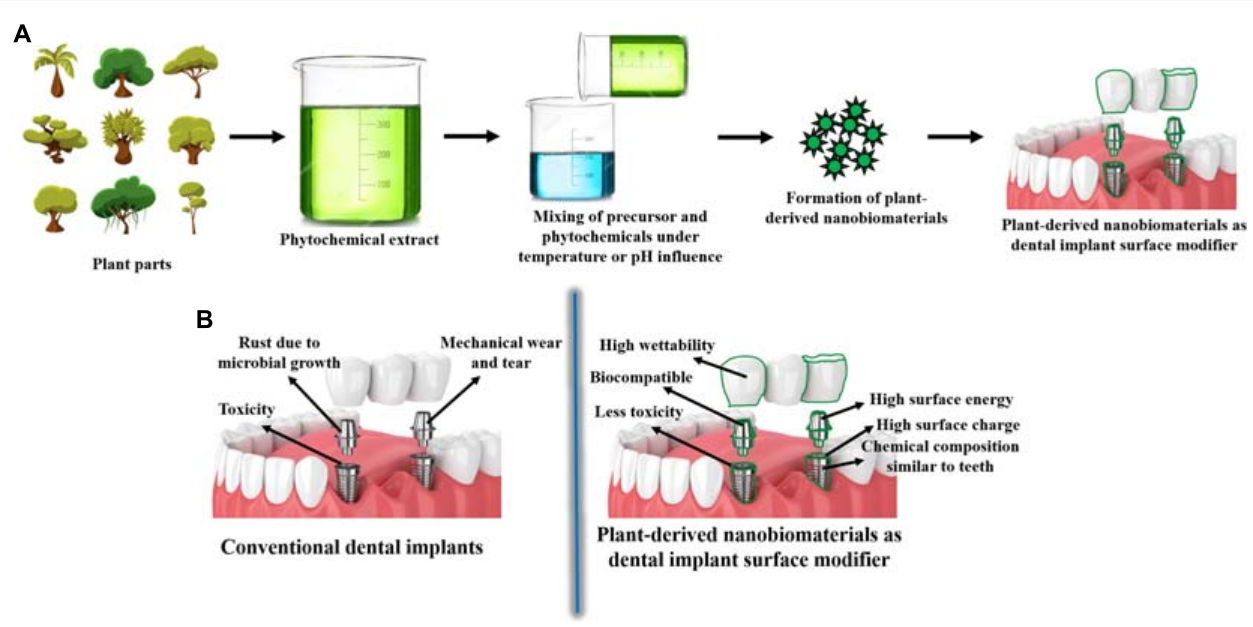

FIGURE 1 | (A) Schematics of nanobiomaterials synthesized from plants for dental implant applications; (B) Schematics showing the limitations of conventional dental implants and advantages of plant-derived nanobiomaterials as surface modifiers of dental implants. 
that the $32.4 \mathrm{~nm}$ sized flake-like shaped silver nanoparticles synthesized via aqueous leaf extract of Mangifera indica, which can be beneficial for the dental restoration applications. "Glass ionomer cement" (GIC) was employed to strengthen the synthesized silver nanobiomaterials, which improved the low wear of conventional GIC, enhanced their mechanical strength with exclusive protective features against Staphylococcus aureus and Escherichia coli. Therefore, these nanobiomaterial reinforced GIC can be useful to improve the mechanical strength of the conventional dental implant materials by blending with them as a composite or as a surface coating to improve their antibacterial activities (Sundeep et al., 2017).

Likewise, the polyphenols extracted from the Anogeissus latifolia plant leaves has been utilized for the fabrication of gold nanobiomaterials for the management of pain in dental tissue implantation applications. The nanobiomaterial exhibited enhanced stability in human serum albumin, cysteine, histidine, and bovine serum albumin, and improved biocompatibility as well as cytocompatibility toward periodontal fibroblasts and erythrocytes in vitro. Further, the study revealed that the gold nanobiomaterial improved the cell viability of MG63 cell lines with strong antinociperceptive activity, which is beneficial for dental pain management applications during tissue implantation (Wang and Wang, 2020). Moreover, plant synthesized zinc oxide nanoparticles has also been proposed to be a potential nanobiomaterial with in vitro osteogenic activity and antibacterial property for dental implant applications (Li Y. et al., 2020). Moreover, silver nanoparticles synthesized via white pepper oleoresin (Paul et al., 2020), Oleo europaea extract (Umai et al., 2020), clove and cinnamon extracts synthesized with zinc oxide nanoparticles (Mohapatra et al., 2020), exhibited enhanced antimicrobial activities against oral pathogens. These can be beneficial as a surface modifier of conventional dental implants, to prevent microbial attacks or infections. All these studies demonstrated that the plantmediated synthesis of nanobiomaterials are highly significant for dental implant applications. It is conceivable that advancements in modern synthesis techniques, will lead to greater success in producing novel phytonanobiomaterials as dental implants.

\section{FUTURE PERSPECTIVES AND CONCLUSION}

It is noteworthy that noteworthy in vitro research findings and breakthroughs are increasingly being reported in the context of plant-synthesized nanobiomaterials for dental implant applications, especially as a surface modifier of

\section{REFERENCES}

Abraham, C. M. (2014). A brief historical perspective on dental implants, their surface coatings and treatments. Open Dent. J. 8, 50-55. doi: 10.2174/ 1874210601408010050

Andra, S., Balu, S. K., Jeevanandham, J., Muthalagu, M., Vidyavathy, M., San Chan, Y., et al. (2019). Phytosynthesized metal oxide nanoparticles for pharmaceutical implants. Nevertheless, numerous challenges and critical shortcomings could also be noticed with regards to plantmediated nanobiomaterial fabrication. Even though, plantmediated synthesis can yield smaller sized bionanomaterials in short time, their stability is not comparable with conventional approaches. Also, the shape of the resultant nanobiomaterials are spherical and polydispersed in most cases and $\mathrm{pH}$ variations are required to transform their morphologies and dispersity. However, addition of chemicals to alter $\mathrm{pH}$ may also lead to increase in toxicity of these phytosynthesized nanobiomaterials. Thus, it is necessary to incorporate novel techniques in plantmediated nanomaterial to eliminate limitations and improve their efficiency. Moreover, there are no reports, which shows that the plant-mediated nanomaterials are toxic or less efficient in dental implant applications. Also, it can be noted that the nanobiomaterials that are synthesized via plant extracts for dental applications in recent times are standalone nanobiomaterials. Hence, nanobiocomposites can be synthesized via plant extracts in the future, to render them beneficial toward large-scale commercial surface-modified dental implant applications with exclusive biomedical properties.

\section{AUTHOR CONTRIBUTIONS}

$\mathrm{JJ}$ and SP conceived and designed the structure of the minireview. JJ contributed to literature exploration and analysis, illustration, and writing the manuscript, which was reviewed, amended, and finalized by SP and MD. All authors ratified the submitted and revised versions.

\section{FUNDING}

SP acknowledges the Open Access funding provided by the Technical University of Munich, Germany. JJ acknowledges the support of FCT-Fundação para a Ciência e a Tecnologia (Base Fund UIDB/00674/2020 and Programmatic Fund UIDP/00674/2020, Portuguese Government Funds), ARDITIAgência Regional para o Desenvolvimento da Investigação Tecnologia e Inovação through the project M1420-01-0145FEDER-000005-CQM ${ }^{+}$(Madeira 14-20 Program).

\section{ACKNOWLEDGMENTS}

The authors thank the reviewers for their valuable feedback and suggestions, which greatly improved the quality of the manuscript.

applications. Naunyn Schmiedebergs Arch. Pharmacol. 392, 755-771. doi: 10. 1007/s00210-019-01666-7

Apaza-Bedoya, K., Tarce, M., Benfatti, C.a.M, Henriques, B., Mathew, M. T., Teughels, W., et al. (2017). Synergistic interactions between corrosion and wear at titanium-based dental implant connections: a scoping review. J. Periodontal Res. 52, 946-954. doi: 10.1111/jre. 12469 
Augustine, R., and Hasan, A. (2020). Emerging applications of biocompatible phytosynthesized metal/metal oxide nanoparticles in healthcare. J. Drug Deliv. Sci. Technol. 56:101516. doi: 10.1016/j.jddst.2020.101516

Bazli, L., Nargesi Khoramabadi, H., Modarresi Chahardehi, A., Arsad, H., Malekpouri, B., Asgari Jazi, M., et al. (2020). Factors influencing the failure of dental implants: a systematic review. J. Compos. Compd. 2, 18-25. doi: $10.29252 /$ jcc. 2.1 .3

Boutinguiza, M., Fernández-Arias, M., Del Val, J., Buxadera-Palomero, J., Rodríguez, D., Lusquiños, F., et al. (2018). Synthesis and deposition of silver nanoparticles on cp Ti by laser ablation in open air for antibacterial effect in dental implants. Mater. Lett. 231, 126-129. doi: 10.1016/j.matlet.2018.07.134

Chrcanovic, B. R., Albrektsson, T., and Wennerberg, A. (2014). Diabetes and oral implant failure: a systematic review. J. Dent. Res. 93, 859-867. doi: 10.1177/ 0022034514538820

Fialho, L., Grenho, L., Fernandes, M. H., and Carvalho, S. (2021). Porous tantalum oxide with osteoconductive elements and antibacterial core-shell nanoparticles: a new generation of materials for dental implants. Mater. Sci. Eng. C 120, 111761. doi: $10.1016 /$ j.msec.2020.111761

Ganguly, P., Breen, A., and Pillai, S. C. (2018). Toxicity of nanomaterials: exposure, pathways, assessment, and recent advances. ACS Biomater. Sci. Eng. 4, 22372275. doi: $10.1021 /$ acsbiomaterials. 8 b00068

Ghiciuc, C.M., Ghiciuc, O.N., Ochiuz, L., and Lupuşoru, C.E. (2017). “Antibacterial effects of metal oxides-containing nanomaterials in dentistry". In Proceedings of the 2017 E-Health and Bioengineering Conference (EHB). Sinaia: IEEE, 365-368.

Goel, S., Dubey, P., Ray, S., Jayaganthan, R., Pant, A. B., and Chandra, R. (2019). Co-sputtered antibacterial and biocompatible nanocomposite titania-zinc oxide thin films on si substrates for dental implant applications. Mater. Technol. 34, 32-42. doi: 10.1080/10667857.2018.1488924

Ha, S.-W., Viggeswarapu, M., Habib, M. M., and Beck, G. R. (2018). Bioactive effects of silica nanoparticles on bone cells are size, surface, and composition dependent. Acta Biomater. 82, 184-196. doi: 10.1016/j.actbio.2018.10.018

Henri Diederich, D. M. D., and Abou-Rabii, I. (2019). The cortically fixed at once approach: a treatment option in an atrophied maxilla. Oral Health Dent. Sci 3, $1-4$.

Huang, Y. S., Mcgowan, T., Lee, R., and Ivanovski, S. (2017). "7.23 Dental Implants: biomaterial properties influencing osseointegration," in Comprehensive Biomaterials II, ed. P. Ducheyne (Oxford: Elsevier), 444-466. doi: 10.1016/b978-0-12-803581-8.09306-1

Jadhav, K., Hr, R., Deshpande, S., Jagwani, S., Dhamecha, D., Jalalpure, S., et al. (2018). Phytosynthesis of gold nanoparticles: characterization, biocompatibility, and evaluation of its osteoinductive potential for application in implant dentistry. Mater. Sci. Eng. C 93, 664-670. doi: 10.1016/j.msec.2018. 08.028

Jamkhande, P. G., Ghule, N. W., Bamer, A. H., and Kalaskar, M. G. (2019). Metal nanoparticles synthesis: an overview on methods of preparation, advantages and disadvantages, and applications. J. Drug Deliv. Sci. Technol. 53:101174. doi: $10.1016 /$ j.jddst.2019.101174

Jeevanandam, J., Chan, Y. S., and Danquah, M. K. (2016). Biosynthesis of metal and metal oxide nanoparticles. ChemBioEng. Rev. 3, 55-67. doi: 10.1002/cben. 201500018

Jeevanandam, J., Kulabhusan, P. K., Sabbih, G., Akram, M., and Danquah, M. K. (2020a). Phytosynthesized nanoparticles as a potential cancer therapeutic agent. 3 Biotech 10:535.

Jeevanandam, J., Sundaramurthy, A., Sharma, V., Murugan, C., Pal, K., Kodous, M. H. A., et al. (2020b). "Sustainability of one-dimensional nanostructures: fabrication and industrial applications," in Sustainable Nanoscale Engineering, eds G. Szekely and A. Livingston (Amsterdam: Elsevier), 83-113.

Kadambi, P., Luniya, P., and Dhatrak, P. (2021). Current advancements in polymer/polymer matrix composites for dental implants: a systematic review. Mater. Today Proc. doi: 10.1016/j.matpr.2020.12.396

Kang, M. S., Lee, J. H., Hong, S. W., Lee, J. H., and Han, D.-W. (2021). Nanocomposites for enhanced osseointegration of dental and orthopedic implants revisited: surface functionalization by carbon nanomaterial coatings. J. Compos. Sci. 5:23doi:

Khan, S. A., and Lee, C.-S. (2020). "Green biological synthesis of nanoparticles and their biomedical applications," in Applications of Nanotechnology for Green Synthesis, eds Inamuddin and A. Asiri (Cham: Springer), 247-280. doi: 10.1007/ 978-3-030-44176-0_10
Kulkarni, A. G., De Britto, S., and Jogaiah, S. (2021). "Economic considerations and limitations of green synthesis vs chemical synthesis of nanomaterials," in Advances in Nano-Fertilizers and Nano-Pesticides in Agriculture, eds S. Jogaiah, H. Bahadur Singh, and R. de Lima (Amsterdam: Elsevier), 459-468. doi: 10. 1016/b978-0-12-820092-6.00018-5

Kulshrestha, S., Khan, S., Meena, R., Singh, B. R., and Khan, A. U. (2014). A graphene/zinc oxide nanocomposite film protects dental implant surfaces against cariogenic Streptococcus mutans. Biofouling 30, 1281-1294. doi: 10. 1080/08927014.2014.983093

Li, J., Jansen, J. A., Walboomers, X. F., and Van Den Beucken, J. J. J. P. (2020). Mechanical aspects of dental implants and osseointegration: a narrative review. J. Mech. Behav. Biomed. Mater. 103:103574. doi: 10.1016/j.jmbbm.2019.103574

Li, S., Duan, Y., Li, R., and Wang, X. (2017). Intracellular and extracellular biosynthesis of antibacterial silver nanoparticles by using Pseudomonas aeruginosa. J. Nanosci. Nanotechnol. 17, 9186-9191. doi: 10.1166/jnn.2017. 13920

Li, Y., Yang, Y., Qing, Y. A., Li, R., Tang, X., Guo, D., et al. (2020). Enhancing ZnO-NP antibacterial and osteogenesis properties in orthopedic applications: a review. Int. J. Nanomed. 15, 6247-6262. doi: 10.2147/ijn.s262876

May, M. C., Andrews, P. N., Daher, S., and Reebye, U. N. (2016). Prospective cohort study of dental implant success rate in patients with AIDS. Int. J. Implant Dent. 2:20.

Mohapatra, S., Leelavathi, L., Meignana, A. I., Pradeep, K. R., and Rajeshkumar, S. (2020). Assessment of antimicrobial efficacy of zinc oxide nanoparticles synthesized using clove and cinnamon formulation against oral pathogensan in vitro study. J. Evol. Med. Dent. Sci. 9, 2034-2040. doi: 10.14260/jemds/ 2020/443

Moniri Javadhesari, S., Alipour, S., and Akbarpour, M. R. (2020). Biocompatibility, osseointegration, antibacterial and mechanical properties of nanocrystalline $\mathrm{Ti}$ $\mathrm{Cu}$ alloy as a new orthopedic material. Colloids Surf. B Biointerfaces 189:110889. doi: 10.1016/j.colsurfb.2020.110889

Neldam, C. A., and Pinholt, E. M. (2012). State of the art of short dental implants: a systematic review of the literature. Clin. Implant Dent. Relat. Res. 14, 622-632. doi: 10.1111/j.1708-8208.2010.00303.x

Osman, R. B., and Swain, M. V. (2015). A critical review of dental implant materials with an emphasis on titanium versus zirconia. Materials 8, 932-958. doi: $10.3390 / \mathrm{ma} 8030932$

Pan, S., Jeevanandam, J., Acquah, C., Tan, K. X., Udenigwe, C. C., and Danquah, M. K. (2021). "Drug delivery systems for cardiovascular ailments," in Drug Delievry Devices and Therapeutic Systems, ed. E. Chappel (Amsterdam: Elsevier), 567-599. doi: 10.1016/b978-0-12-819838-4.00019-5

Park, J.-H., Odkhuu, M., Cho, S., Li, J., Park, B.-Y., and Kim, J.-W. (2020). 3Dprinted titanium implant with pre-mounted dental implants for mandible reconstruction: a case report. Maxillofac. Plast. Reconstr. Surg. 42:28.

Parnia, F., Yazdani, J., Javaherzadeh, V., and Dizaj, S. M. (2017). Overview of nanoparticle coating of dental implants for enhanced osseointegration and antimicrobial purposes. J. Pharm. Pharm. Sci. 20, 148-160. doi: 10.18433/ j3gp6g

Paul, R. P., Roy, A., and Shanmugam, R. (2020). Antibacterial activity of white pepper oleoresin mediated silver nanoparticles against oral pathogens. J. Evol. Medi. Dent. Sci. 9, 2352-2356. doi: 10.14260/jemds/ 2020/510

Peng, J.-M., Lin, J.-C., Chen, Z.-Y., Wei, M.-C., Fu, Y.-X., Lu, S.-S., et al. (2017). Enhanced antimicrobial activities of silver-nanoparticle-decorated reduced graphene nanocomposites against oral pathogens. Mater. Sci. Eng. C 71, 10-16. doi: 10.1016/j.msec.2016.09.070

Prakasam, M., Locs, J., Salma-Ancane, K., Loca, D., Largeteau, A., and BerzinaCimdina, L. (2017). Biodegradable materials and metallic implants-a review. J. Funct. Biomater. 8:44. doi: 10.3390/jfb8040044

Qu, Y., He, F., Yu, C., Liang, X., Liang, D., Ma, L., et al. (2018). Advances on graphene-based nanomaterials for biomedical applications. Mater. Sci. Eng. C 90, 764-780.

Rasouli, R., Barhoum, A., and Uludag, H. (2018). A review of nanostructured surfaces and materials for dental implants: surface coating, patterning and functionalization for improved performance. Biomater. Sci. 6, 1312-1338. doi: $10.1039 / \mathrm{c} 8 \mathrm{bm} 00021 \mathrm{~b}$

Roguska, A., Belcarz, A., Zalewska, J., Hołdyñski, M., Andrzejczuk, M., Pisarek, M., et al. (2018). Metal TiO2 nanotube layers for the treatment of dental implant 
infections. ACS Appl. Mater. Interfaces 10, 17089-17099. doi: 10.1021/acsami. 8 b04045

Rupp, F., Liang, L., Geis-Gerstorfer, J., Scheideler, L., and Hüttig, F. (2018). Surface characteristics of dental implants: a review. Dent. Mater. 34, 40-57. doi: 10. 1016/j.dental.2017.09.007

Sanguida, A., Vinothini, V., Prathima, G. S., Santhadevy, A., Premlal, K., and Kavitha, M. (2019). Age and reasons for first dental visit and knowledge and attitude of parents toward dental procedures for Puducherry children aged 0-9 years. J. Pharm. Bioallied Sci. 11:S413.

Shah, K. C., Chao, D., Wu, B. M., and Jensen, O. T. (2019). Shape-memory retained complete arch guided implant treatment using nitinol (Smileloc) abutments. Oral and Maxillofac. Surg. Clin. 31, 427-435. doi: 10.1016/j.coms.2019.03.005

Shanmuganathan, R., Karuppusamy, I., Saravanan, M., Muthukumar, H., Ponnuchamy, K., Ramkumar, V. S., et al. (2019). Synthesis of Silver nanoparticles and their biomedical applications-A comprehensive review. Curr. Pharm. Des. 25, 2650-2660. doi: 10.2174/1381612825666190708185506

Sundeep, D., Vijaya Kumar, T., Rao, P. S. S., Ravikumar, R. V. S. S. N., and Gopala Krishna, A. (2017). Green synthesis and characterization of Ag nanoparticles from Mangifera indica leaves for dental restoration and antibacterial applications. Prog. Biomater. 6, 57-66. doi: 10.1007/s40204-0170067-9

Takanche, J. S., Kim, J.-E., Kim, J.-S., Lee, M.-H., Jeon, J.-G., Park, I.-S., et al. (2018). Chitosan-gold nanoparticles mediated gene delivery of c-myb facilitates osseointegration of dental implants in ovariectomized rat. Artif. Cells Nanomed. Biotechnol. 46, S807-S817.

Tan, K. X., Jeevanandam, J., Pan, S., Yon, L. S., and Danquah, M. K. (2020). Aptamer-navigated copolymeric drug carrier system for in vitro delivery of $\mathrm{MgO}$ nanoparticles as insulin resistance reversal drug candidate in Type 2 diabetes. J. Drug Deliv. Sci. Technol. 57:101764. doi: 10.1016/j.jddst.2020. 101764

Tan, K. X., Pan, S., Jeevanandam, J., and Danquah, M. K. (2019). Cardiovascular therapies utilizing targeted delivery of nanomedicines and aptamers. Int. J. Pharam. 558, 413-425. doi: 10.1016/j.ijpharm.2019.01.023

Travess, H. C., Williams, P. H., and Sandy, J. R. (2004). The use of osseointegrated implants in orthodontic patients: 2. absolute anchorage. Dent. Update 31, 355-362. doi: 10.12968/denu.2004.31.6.355

Umai, D., Vikranth, A., and Meenambiga, S. S. (2020). A study on the green synthesis of silver nanoparticles from Olea europaea and its activity against oral pathogens. Mater. Today Proc. 6:e04493
Vogel, R., Smith-Palmer, J., and Valentine, W. (2013). Evaluating the health economic implications and cost-effectiveness of dental implants: a literature review. Int. J. Oral Maxillofac. Implants 28, 343-356. doi: 10.11607/jomi. 2921

Wang, M., and Wang, L. (2020). Plant polyphenols mediated synthesis of gold nanoparticles for pain management in nursing care for dental tissue implantation applications. J. Drug Deliv. Sci. Technol 58:101753. doi: 10.1016/j. jddst.2020.101753

Woźniak, W., and Markuszewski, J. (2019). Osseointegration of hydroxyapatite coatings doped with silver nanoparticles: scanning electron microscopy studies on a rabbit model. Folia morphol. 78, 107-113. doi: 10.1111/j.1365-2818.1993. tb03364.x

Yadav, V. K., Khan, S. H., Malik, P., Thappa, A., Suriyaprabha, R., Ravi, R. K., et al. (2020). "Microbial synthesis of nanoparticles and their applications for wastewater treatment," in Microbial Biotechnology: Basic Research and Applications, eds J. Singh, A. Vyas, S. Wang, and R. Prasad (Singapore: Springer), 147-187. doi: 10.1007/978-981-152817-0_7

Zafar, M. S., Alnazzawi, A. A., Alrahabi, M., Fareed, M. A., Najeeb, S., and Khurshid, Z. (2019). "18 - Nanotechnology and nanomaterials in dentistry," in Advanced Dental Biomaterials, eds Z. Khurshid, S. Najeeb, M. S. Zafar, and F. Sefat (Cambridge: Woodhead Publishing), 477-505. doi: 10.1016/b978-0-08102476-8.00018-9

Zhang, J., Tang, H., Liu, Z., and Chen, B. (2017). Effects of major parameters of nanoparticles on their physical and chemical properties and recent application of nanodrug delivery system in targeted chemotherapy. Int. J. Nanomed. 12:8483. doi: 10.2147/ijn. s148359

Conflict of Interest: The authors declare that the research was conducted in the absence of any commercial or financial relationships that could be construed as a potential conflict of interest.

Copyright (C) 2021 Jeevanandam, Danquah and Pan. This is an open-access article distributed under the terms of the Creative Commons Attribution License (CC BY). The use, distribution or reproduction in other forums is permitted, provided the original author(s) and the copyright owner(s) are credited and that the original publication in this journal is cited, in accordance with accepted academic practice. No use, distribution or reproduction is permitted which does not comply with these terms. 